\title{
Androstenedione Production and Interconversion Rates Measured in Peripheral Blood and Studies on the Possible Site of Its Conversion to Testosterone *
}

\author{
R. Horton † AND J. F. TAIT $\ddagger$ \\ (From the Worcester Foundation for Experimental Biology, Shrewsbury, Mass.)
}

The present aim of in vivo studies of steroid dynamics in the androgen field is to obtain estimates of the total rate of entry of testosterone and its major precursors such as androstenedione into the general circulation, i.e., the blood production rates (1-7). Also required are the secretion rates of this steroid and its precursors, the relative contributions of these secretions to the blood production rates, and a knowledge of the original anatomical sites of these interconversions and secretions.

Previous approaches and solutions to these problems have been questioned because in certain situations, when urinary and blood production rate estimates differ, the total rate of entry of steroid into the general circulation cannot be obtained from urinary studies $(6,7)$. Also the metabolism of a secreted steroid and the same steroid produced from precursor cannot be regarded as being equivalent (8), which is the basic assumption of one urinary approach (2) and one combined blood and urinary approach (6) used to calculate secretion rates. Presumably, both the production and mode of metabolism of a steroid may vary at different anatomical sites $(5,8-10)$.

To avoid these difficulties, we have measured production and interconversion rates of testosterone and androstenedione directly in the peripheral circulation. Because the output of steroids from endocrine glands is into the same circulation,

\footnotetext{
* Submitted for publication August 30, 1965 ; accepted November 18, 1965.

This work was supported by U. S. Public Health Service grants AM-08387 and AM-03179.

Presented in part at the Forty-seventh Meeting of the Endocrine Society, New York, June 1965.

† American Cancer Society Investigator PF-256.

Address requests for reprints to Dr. R. Horton, Dept. of Medicine, University of California at Los Angeles, Los Angeles, Calif.

$\ddagger$ Recipient of U. S. Public Health Service Research Career Program Award GM-K6-18322.
}

the secretion rate is a higher proportion of the blood production compared with the corresponding urinary production rate in situations when the two estimates differ (8). The approach using blood measurements would then be expected to lead to more precise estimates of secretion rates.

\section{Methods}

Normal adults, aged 21 to 33 , were used in these studies. All female subjects gave histories of normal and regular menstrual cycles, were in excellent general health, and received no medications. Plasma testosterone and androstenedione in plasma were estimated by a double isotope derivative technique using thiosemicarbazide- ${ }^{\star} \mathrm{S}$ as reagent $(11,12)$. Ten $\mathrm{ml}$ of plasma was obtained from fasting subjects between 8 and 9 a.m. and, after addition of tritiated indicator to allow for losses, was frozen for later assay. Unless otherwise stated, plasma specimens for the subjects in this study were obtained before the start of the continuous infusion used to determine clearance values. This was done to avoid any possible effect of the infusion on plasma concentrations due, for example, to stress of the procedure.

Benzene, toluene, ethyl acetate, and methanol used for the chromatographic systems were spectrograde.1 Pyridine and acetic anhydride were prepared as described for estimation of testosterone (11). Materials and procedures for the thiosemicarbazide- ${ }^{* S}$ methods were as described elsewhere $(11,12)$. Propylene glycol and anhydrous ether ${ }^{2}$ were used without further purification. The ${ }^{8} \mathrm{H}$ - and ${ }^{14} \mathrm{C}$-labeled steroids (testosterone-4- ${ }^{2 \mathrm{C}} \mathrm{C}$ and androstenedione-4- ${ }^{11} \mathrm{C}$, testosterone-1,2- ${ }^{\circ} \mathrm{H}$ and androstenedione-1,2- $-\mathrm{H})^{8}$ were further purified by partition chromatography on Celite in the Bush B-3 system (stationary phase: methanol, water, 4:1; mobile phase: Skellysolve C, benzene, 2:1). Androstenedione- $H$ and ${ }^{14} \mathrm{C}$ were made by oxidation of testosterone-1,2- ${ }^{8} \mathrm{H}$ and ${ }^{14} \mathrm{C}$ with $0.2 \mathrm{ml} 0.5 \%$ chromium trioxide in $95 \%$ acetic acid for 1 hour in the dark, dilution with $1 \mathrm{ml} 20 \%$ ethanol, and extraction with methylene chloride (spectrograde).1 The washed extract taken to dryness was then chromatographed on the Celite column.

\footnotetext{
1 Mallinckrodt, St. Louis, Mo.

2 Merck, Philadelphia, $\mathrm{Pa}$.

8 We would like to thank Dr. Marcel Gut of the Worcester Foundation for supplying the labeled steroids.
} 
Testosterone and androstenedione carrier steroid ran, in all systems used, as a single compound as detected by absorption of ultraviolet light (254 $\mathrm{m \mu})$.'

Thin layer chromatography $(T L C)$. The initial separation from plasma in the clearance rate determination was with alumina 4 thin layer ( $300 \mu$ thick) on glass plates with the system benzene, ethyl acetate, $3: 2$, developed in a single direction. The plate was heated to $100^{\circ} \mathrm{C}$ for 1 hour and stored in a desiccator before use. This TLC with alumina will separate testosterone from epitestosterone and androstanediol, and androstenedione from androsterone and etiocholanolone. The capacity of the system allows the use of an ether extract of 50 $\mathrm{ml}$ plasma as a $1-\mathrm{cm}$ streak with adequate resolution of these steroids in 2 hours.

Paper chromatography. The second chromatography system in the clearance work was a modified Bush A system (stationary phase: methanol, water, 0.85: 0.15; mobile phase: Skellysolve C). The system was equilibrated for 5 hours and developed for 12 hours. The carrier steroids were located by their absorption of ultraviolet light $(254 \mathrm{~m} \mu)$.

The combination of these two systems separated the two steroids from all expected metabolites.

Radioactive counting. All counting was performed with a Nuclear-Chicago liquid scintillation spectrometer, model 725. For the clearance and conversion work the dried samples were rinsed three times with $0.2 \mathrm{ml} \mathrm{ab}-$ solute ethanol and transferred to $10 \mathrm{ml}$ toluene containing $0.4 \%$ diphenyloxazole and $0.005 \%$ 1,4-bis-2-(5-phenyloxazolyl) benzene. Discrimination and gain settings were such to give an efficiency of $40 \%$ for ${ }^{14} \mathrm{C}\left({ }^{3} \mathrm{H}\right.$ then $0.1 \%$ ) and $12 \%$ for ${ }^{3} \mathrm{H}\left({ }^{14} \mathrm{C}\right.$ then $\left.15 \%\right)$ with backgrounds of 7 and $24 \mathrm{cpm}$, respectively. Samples were counted five times for $\mathbf{4 0}$ minutes each and gave a $\mathrm{SE}$ of less than $5 \%$.

Measurement of metabolic clearance rate of androstenedione and testosterone. A priming dose of $3 \mu \mathrm{c} 1,2-{ }^{2} \mathrm{H}-$ labeled androstenedione or testosterone $(0.022 \mu \mathrm{g}$, SA $137 \mu \mathrm{c}$ per $\mu \mathrm{g}$ ) was injected intravenously in $10 \mathrm{ml}$ sterile isotonic saline over a 2 -minute period to prone, fasting subjects at about 8:30 a.m. One half hour later, a constant continuous infusion of a total of 7 to $10 \mu \mathrm{c}{ }^{8} \mathrm{H}$ labeled steroid $(0.05$ to $0.07 \mu \mathrm{g})$ in $50 \mathrm{ml}$ of $8 \%$ ethanol in isotonic saline was started with a Harvard infusion pump fitted with a $50-\mathrm{ml}$ Yale infusion syringe. The infusion at a calibrated rate of $0.382 \mathrm{ml}$ per minute was given through a three-way stopcock with 20 -inch extension tubing into the left median basilic vein through a size 21 needle. Whole blood $(50 \mathrm{ml})$ was drawn into heparinized disposable plastic syringes from the right arm at 85, 100, and 115 minutes after the start of the infusion. Samples of the infusion solution were obtained both from the syringe and from the tubing. The blood was immediately centrifuged and the plasma removed and cooled with ice in $50-\mathrm{ml}$ measuring cylinders. Fifty $\mu \mathrm{g}$ carrier steroid, ${ }^{11} \mathrm{C}$ indicator (180 to $200 \mathrm{cpm}$ ) in $0.2 \mathrm{ml}$

\footnotetext{
4 Neutral alumina, E. Merck GF 254, distributed by Brinkmann Instruments, Great Neck, N. Y.
}

ethanol, and $2 \mathrm{ml} 3 \mathrm{~N} \mathrm{NaOH}$ were mixed with the plasma in a 125-ml separatory funnel and the steroids extracted twice with 2 vol cold ether. The ether was then washed twice with $\frac{1}{10}$ vol $\mathrm{H}_{2} \mathrm{O}$ and the extract dried in vacuo and spotted on the alumina thin layer plate. After running in this system in one dimension, the carrier steroids were located under a 254-m $\mu$ ultraviolet lamp, marked, and aspirated under low vacuum into a pipette packed with glass wool. The inverted pipette was then eluted with $10 \mathrm{ml}$ ethanol and the eluate taken to dryness. This extract was next streaked over a $2-\mathrm{cm}$ line on Whatman 2 paper and run in the Bush A system for 12 hours. The area was then cut out and eluted with $10 \mathrm{ml}$ ethanol with a $15-\mathrm{ml}$ syringe fitted with a 25 -gauge needle ( $R_{\mathrm{f}}$ testosterone 0.3 , androstenedione 0.5$)$. The dried extract was transferred to counting vials. The metabolic clearance rate by constant infusion was calculated as the rate of radioactive infusion divided by the plasma radioactivity per liter corrected for recovery and measured specifically as the same steroid as that infused (13).

Conversion rate determination in blood. The conversion rates in blood were performed as part of the continuous infusion clearance rate determinations. To the plasma specimens, carrier and ${ }^{14} \mathrm{C}$ indicator of the product steroid were also added (i.e., after infusion of androstenedione- ${ }^{8} \mathrm{H}$, addition of both ${ }^{11} \mathrm{C}$ and carrier androstenedione and testosterone). The product steroid was also isolated from plasma by the TLC and paper systems. This procedure was usually carried out for the last two plasma samples (Table I) and the mean value taken for further calculations. The conversion factor in plasma was calculated as ratio of product to precursor in counts per minute per liter all corrected for recovery $\left[x^{T} / x^{\Lambda}\right.$ after infusion of radioactive androstenedione $(R x)$ and $z^{\mathbf{A}} / z^{\mathbf{T}}$ after radioactive testosterone $(\mathbf{R z})$ ].

Hepatic extraction of testosterone produced in the liver. Androstenedione- ${ }^{11} \mathrm{C}$ (total $4 \mu \mathrm{c}$, for 2 hours) prepared in a similar manner to the tritiated steroid was administered by continuous infusion through a $30-\mathrm{cm}$ Tygon tube placed into a nasogastric tube (size 12 French) inserted into the lower stomach. Plasma specimens were handled as for the routine clearance and interconversion rate studies in two experiments. However, in one male and one female subject, testosterone- ${ }^{8} \mathrm{H}$ (total $10 \mu \mathrm{c}$, for 2 hours) was also infused simultaneously with the gastric infusion but into the left basilic vein. In these experiments, the ${ }^{11} \mathrm{C} /{ }^{3} \mathrm{H}$ ratios of testosterone in plasma and of the testosterone released from urinary testosterone glucuronide were determined and compared with one another and also with the ${ }^{8} \mathrm{H} /{ }^{\mu c} \mathrm{C}$ ratio of the infused material (androstenedione- ${ }^{14} \mathrm{C}$ and testosterone- ${ }^{8} \mathrm{H}$ infused in the same time interval). For both urine and blood, carrier steroid but not radioactive indicators was added for these two experiments. Urine was collected for 48 hours, pooled, and a $\frac{1}{10}$ aliquot of the total analyzed in duplicate. The urine, after two preliminary extractions with 1 vol methylene chloride, was adjusted to $\mathrm{pH} 4.6$ with potassium acetate-acetic acid buffer and incubated with $500 \mathrm{U}$ per $\mathrm{ml} \beta$-glucuronidase (Ketodase) at $37^{\circ} \mathrm{C}$ for 24 hours in a stoppered flask. The urine was then 
TABLE I

Data for the determination of $M C R^{\Lambda}, M C R^{T}, x^{A} / x^{T}$, and $z^{T} / z^{A}$

\begin{tabular}{|c|c|c|c|c|c|c|c|c|c|c|c|c|}
\hline \multirow[b]{2}{*}{ Subject } & \multirow[b]{2}{*}{ Sex } & \multirow{2}{*}{$\begin{array}{c}\text { Cpm/day } \\
\text { infused } \\
\text { androstene- } \\
\text { dione--2 } \mathrm{H}^{*}\end{array}$} & \multicolumn{4}{|c|}{$\begin{array}{l}\text { Cpm/L plasmat androstenedi- } \\
\text { one }\left(\mathbf{x}^{\mathbf{A}}\right) \text { after priming dose }\end{array}$} & \multirow[b]{2}{*}{ MCRA $\ddagger$} & \multicolumn{3}{|c|}{$\begin{array}{c}\mathrm{Cpm} / \mathrm{L} \text { plasma testos- } \\
\text { terone }\left(\mathbf{x}^{\mathrm{T}}\right) \text { after } \\
\text { priming dose } \\
\end{array}$} & \multirow[b]{2}{*}{$x^{T} / x^{A}$} & \multirow[b]{2}{*}[\rho]{$_{\mathrm{BB}^{\mathrm{A}}} \mathrm{AT}_{\S}$} \\
\hline & & & $\begin{array}{l}115 \\
\min \end{array}$ & $\begin{array}{l}130 \\
\text { min }\end{array}$ & $\begin{array}{l}145 \\
\min \end{array}$ & Mean & & $\begin{array}{l}130 \\
\min \end{array}$ & $\begin{array}{l}145 \\
\mathrm{~min}\end{array}$ & Mean & & \\
\hline & & & & & & & $L / d a y$ & & & & & \\
\hline 1. K.R. & $\mathbf{M}$ & $5.76 \times 10^{6}$ & & ooled pla & ma & 2,020 & 2,850 & Pooled & 1 plasma & 222 & 0.11 & 0.046 \\
\hline 2. M.M. & $\mathbf{M}$ & $11.3 \times 10^{6}$ & 4,850 & 5,050 & 5,100 & 5,000 & 2,260 & 1,230 & 1,190 & 1,210 & 0.24 & 0.10 \\
\hline 3. R.H. & $\mathbf{M}$ & $11.0 \times 10^{6}$ & 4,300 & 4,600 & $\mathbf{4 , 4 8 0}$ & 4,460 & 2,470 & 480 & 505 & 492 & 0.11 & 0.046 \\
\hline 4. C.P. & $\mathbf{M}$ & $16.6 \times 10^{6}$ & 7,500 & 7,450 & 7,550 & 7,550 & 2,220 & 660 & 780 & 720 & 0.095 & 0.040 \\
\hline 5. N.G. & $\mathbf{M}$ & $15.1 \times 10^{6}$ & 5,100 & 5,470 & 5,220 & 5,260 & 2,860 & 320 & 324 & .322 & 0.062 & 0.026 \\
\hline 6. G.M. & $\mathbf{M}$ & $14.75 \times 10^{6}$ & 7,720 & 7,900 & 7,500 & 7,700 & 1,920 & 1,110 & 1,400 & 1,250 & 0.16 & 0.067 \\
\hline 7. L.M. & F & $5.93 \times 10^{6}$ & 2,060 & 1,980 & 2,020 & 2,020 & 2,940 & 294 & 290 & 292 & 0.145 & 0.061 \\
\hline 8. D.B. & F & $12.25 \times 10^{6}$ & 6,520 & 5,850 & 5,670 & 6,010 & 2,037 & 1,180 & 1,100 & 1,140 & 0.19 & 0.080 \\
\hline 9. J.F. & F & $17.3 \times 10^{6}$ & 8,000 & 7,900 & 8,100 & 8,000 & 2,160 & 1,040 & 980 & 1,010 & 0.125 & 0.052 \\
\hline 10. P.N. & F & $16.25 \times 10^{6}$ & 7,380 & 7,380 & 7,600 & $\mathbf{7 , 4 7 0}$ & 2,220 & 940 & 870 & 905 & 0.12 & 0.050 \\
\hline 11. J.R. & F & $15.5 \times 10^{6}$ & 9,050 & 8,460 & 8,400 & 8,630 & 1,800 & 1,040 & 1,200 & 1,120 & 0.13 & 0.055 \\
\hline 12. D.B. & F & $22.1 \times 10^{6}$ & \multicolumn{3}{|c|}{ Pooled plasma } & 9,810 & 2,250 & \multicolumn{2}{|c|}{ Pooled plasma } & 2,190 & 0.22 & 0.094 \\
\hline \multirow[t]{3}{*}{ Mean $\pm \mathrm{SE}$} & & & & & & & $2,330 \pm 107$ & & & & $0.14 \pm 0.01$ & $0.059 \pm 0.005$ \\
\hline & & \multirow{2}{*}{$\begin{array}{l}\text { Cpm/day } \\
\text { infused } \\
\text { testoster- } \\
\text { one-2. } \mathrm{H}^{*}\end{array}$} & \multicolumn{4}{|c|}{$\begin{array}{c}\mathrm{Cpm} / \mathrm{L} \text { plasmat testosterone }\left(\mathrm{z}^{\mathrm{T}}\right) \\
\text { after priming dose }\end{array}$} & & \multicolumn{3}{|c|}{$\begin{array}{l}\text { Cpm/L plasma andros- } \\
\text { tenedione }\left(\mathbf{z}^{\mathrm{T}}\right) \text { after } \\
\text { priming dose }\end{array}$} & & \\
\hline & & & $\begin{array}{l}115 \\
\min \end{array}$ & $\begin{array}{l}130 \\
\mathrm{~min}\end{array}$ & $\begin{array}{l}145 \\
\mathrm{~min}\end{array}$ & Mean & $\mathbf{M C R}^{\mathrm{T}} \ddagger$ & $\begin{array}{l}130 \\
\min \end{array}$ & $\begin{array}{l}145 \\
\mathrm{~min}\end{array}$ & Mean & $z^{A} / z^{T}$ & {$[\rho]_{\mathrm{BB}^{\mathrm{TA}}} \delta$} \\
\hline & & & & & & & $L / d a y$ & & & & & \\
\hline 1. N.G. & $\mathbf{M}$ & $24.2 \times 10^{6}$ & 19,300 & 19,700 & 19,500 & 19,500 & 1,240 & 380 & 400 & 390 & 0.020 & 0.046 \\
\hline 2. M.M. & $\mathbf{M}$ & $25.3 \times 10^{6}$ & & 24,000 & 22,800 & 23,400 & 1,080 & 770 & 730 & 750 & 0.032 & 0.076 \\
\hline 3. C.P. & $\mathbf{M}$ & $41.4 \times 10^{6}$ & 40,000 & 42,000 & 39,800 & 40,600 & 1,020 & 1,290 & 1,230 & 1,260 & 0.031 & 0.073 \\
\hline 4. L.N. & $\mathbf{F}$ & $34.2 \times 10^{6}$ & 37,000 & 31,000 & 34,800 & 34,300 & 995 & 1,170 & 1,150 & 1,160 & 0.034 & 0.080 \\
\hline 5. J.F. & $\mathbf{F}$ & $26.2 \times 10^{6}$ & 37,200 & 31,200 & 34,440 & 34,300 & 765 & 970 & 940 & 955 & 0.028 & 0.066 \\
\hline Mean $\pm \mathrm{SE}$ & & & & & & & $1,020 \pm 80$ & & & & $0.028 \pm 0.002$ & $0.066 \pm 0.008$ \\
\hline
\end{tabular}

* Sample obtained from tubing during infusion.

$+{ }^{\mathrm{a}} \mathrm{H}$ (counts per minute per liter) corrected for losses with ${ }^{14} \mathrm{C}$ indicator.

$¥$ MCRA and MCRT $=$ metabolic clearance rate of androstenedione and testosterone

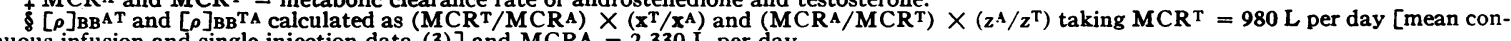

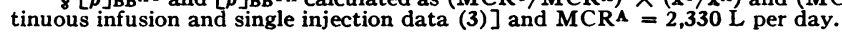

cooled with ice water and extracted twice with 1.5 vol ether with added $60 \mu \mathrm{g}$ carrier testosterone. The ether extract was washed twice with $\frac{1}{10}$ vol $1 \mathrm{~N} \mathrm{NaOH}$ and twice with $\frac{1}{10}$ vol $\mathrm{H}_{2} \mathrm{O}$. The dried extract was then chromatographed in the alumina thin layer system then on paper in the Bush A system as described for the plasma separation. The dried eluate from paper was then reacted overnight at room temperature in the dark with $0.3 \mathrm{ml}$ pyridine and $0.15 \mathrm{ml}$ acetic anhydride. One-tenth $\mathrm{ml}$ ethanol hastened drying under vacuum, and the extract was rechromatographed for 4 hours with parallel running testosterone acetate in the A system. The eluate from the area corresponding to the acetylated steroid was transferred to counting vials as described above and the isotope ratio determined. Total urinary excretion was determined by counting $0.3-\mathrm{ml}$ portions of urine and all samples and standards in a scintillation fluid consisting of $0.3 \mathrm{ml}$ urine, $6 \mathrm{ml}$ ethanol, and $10 \mathrm{ml}$ toluene. The toluene contained $0.4 \%$ diphenyloxazole and $0.005 \% 1,4-$ bis-2-(5-phenyloxazolyl) benzene. The settings were altered on the scintillation counter to the balance point for ${ }^{14} \mathrm{C}$ counting in this mixture.

Evidence for radiochemical purity of the labeled steroids infused. The labeled steroids were all chromatographed on a (30-g, 15-ml stationary phase) Celite column with either the Bush A or Bush B3 system taking only two 5-ml peak fractions. Evidence for purity is dependent upon the demonstration of constancy of the ${ }^{3} \mathrm{H} /{ }^{14} \mathrm{C}$ ratio after addition of ${ }^{14} \mathrm{C}$-labeled steroid initially and of samples taken after alumina TLC and paper chromatography (e.g., initial androstenedione ratio after column, 16.9; ratio after TLC, 16.8; and after paper chromatography, 16.8).

Evidence for radiochemical purity of labeled androstenedione and testosterone isolated from plasma during continuous infusion. In this study, all three plasma samples obtained from an infusion were pooled $(75 \mathrm{ml})$ and ${ }^{14} \mathrm{C}$ indicator and carrier of the infused steroid added, and after the TLC and Bush A paper chromatography, onethird was taken for counting. The remaining extract was dried under vacuum and for androstenedione was reacted with $1 \mathrm{mg}$ thiosemicarbazide in $0.5 \mathrm{ml}$ methanol and $0.05 \mathrm{ml}$ glacial acetic acid overnight at $48^{\circ} \mathrm{C}$ in a $25-\mathrm{ml}$ round-bottom stoppered flask. The androstenedione 3,17bisthiosemicarbazone derivative with $20 \mu \mathrm{g}$ carrier was extracted twice, after addition of $1 \mathrm{ml}$ aqueous $5.9 \%$ sodium carbonate with methylene chloride, $6 \mathrm{ml}$, and the dried extract run for 24 hours in a $20 \%$ toluene-propylene 
glycol system. For testosterone in a similar study, after the Bush A chromatography, the extract was acetylated with pyridine and acetic anhydride and the dried extract rechromatographed in the Bush A system for 4 hours ( $R_{\mathrm{f}} 0.8$, testosterone acetate). In both studies the isotope ratios after further derivative formation were unchanged within the limits of counting error $( \pm 2 \%)$. The ratio ${ }^{3} \mathrm{H} /{ }^{14} \mathrm{C}$ of androstenedione after the Bush $\mathrm{A}$ was 2.41 , as the thiosemicarbazone 2.36 ; the ratio ${ }^{8} \mathrm{H} /{ }^{12} \mathrm{C}$ of testosterone after the Bush $\mathrm{A}$ was 14.7, as acetate 14.4.

Evidence for radiochemical purity of testosterone-" $H$ and androstenedione- ${ }^{-} \mathrm{H}$ obtained in plasma from precursor steroid. After continuous infusion of androstenedione- ${ }^{8} \mathrm{H}$, a pool of the plasma samples obtained with added testosterone ${ }^{-14} \mathrm{C}$ and carrier testosterone was carried through the TLC and paper systems. Again a sample was taken for counting, the remainder acetylated, and the testosterone acetate rerun in the Bush A system. The ${ }^{14} \mathrm{C} /{ }^{3} \mathrm{H}$ ratio of the product was essentially unchanged after derivative formation $\left({ }^{11} \mathrm{C} /{ }^{\circ} \mathrm{H}\right.$ ratio 4.38 after routine separation and 4.44 after acetylation and further chromatography). The conversion rate in this female subject was $15 \%$, which was about the normal mean value.

Evidence for the radiochemical purity of androstenedione- ${ }^{8} \mathrm{H}$ after infusion of testosterone- ${ }^{8} \mathrm{H}$ was difficult to demonstrate, since the conversion rate was in all cases less than $3 \%$. Although the resultant radioactivity was sufficient for reasonably accurate interconversion measurements, after paper chromatography it was so low as to preclude further extensive study particularly since the formation of the thiosemicarbazone derivative and further chromatography gave low recoveries. Evidence for radiochemical isolation for this conversion rests on the almost identical ${ }^{11} \mathrm{C} /{ }^{3} \mathrm{H}$ ratio obtained after the alumina TLC and the subsequent Bush $\mathrm{A}$ paper chromatography (7.0 and $7.2,2 \%$ statistical counting error) in the investigation of one pooled sample after infusion of radioactive testosterone. The interconversion rate was about equal to the normal mean in this subject.

Evidence that equilibrium in plasma was attained during the continuous infusion. Analysis of radioactivity as the purified ${ }^{8} \mathrm{H}$-labeled steroid (same as infused steroid) corrected for recovery from the three plasma specimens obtained at 115, 130, and 145 minutes after the priming dose does not indicate a trend in values. If the value at 130 minutes is taken as comparison, the mean value at 115 minutes was $100 \pm 2$ (SE) and at 145 minutes $99 \pm 1 \%$ (SE) for the androstenedione radioactivity after androstenedione- ${ }^{8} \mathrm{H}$ infusion and $108 \pm 7$ (SE) at 115 minutes and $102 \pm 3 \%(\mathrm{SE})$ at 145 minutes for testosterone radioactivity after testosterone infusion. Both these analyses showed no significant trend in values.

The mean deviation of the product steroids, testosterone- ${ }^{-2} \mathrm{H}$ and androstenedione- ${ }^{-} \mathrm{H}$, of the individual values at 130 minutes and 145 minutes from their mean was $5 \%$, maximum $14 \%$ and $2 \%$, maximum $3 \%$ (Table I). In two experiments when the radioactivity as the product in all three plasma samples $(115,130$, and 145 minutes after the priming dose) was measured, there was no significant trend in the values.

Indication that high specific activity nonpolar C-19 steroids can adsorb to glass and plastic tubing. Initial evidence was obtained that high specific activity ${ }^{\text {"H-labeled }}$ steroid diluted with isotonic saline could be significantly adsorbed to the glass of an infusion syringe over a 2hour period. This was particularly true for the more nonpolar androstenedione-1,2- ${ }^{\circ} \mathrm{H}$. This difficulty was eliminated by increasing the solubility of the steroid in the infusion solution by using $8 \%$ ethanol in sterile isotonic saline. However, for androstenedione there was still the problem of adsorption to the sterile polyethylene tubing, which with low infusion rates could be significant (12 to $16 \%$ ). This effect was not completely eliminated, but with a constant infusion the delivery of labeled steroids from the tubing was found to be unchanged throughout the infusion, and sampler could be removed from the tubing for counting and the true infusion rate of labeled steroid into the subject calculated. This latter difficulty was insignificant for the more polar testosterone. Recent experience has indicated in the nasogastric infusion study that Teflon tubing will not adsorb to any degree either steroid, and so Teflon tubing was used as an inner lining to the usual nasogastric tube.

Conversion of androstenedione to testosterone after withdrawal of blood. Fifty $\mathrm{ml}$ whole blood freshly drawn into heparinized syringes was incubated for 1 hour at room temperature with androstenedione- ${ }^{8} \mathrm{H}$. After centrifugation, the plasma with testosterone- ${ }^{10} \mathrm{C}$ indicator and carrier was processed as for the study of metabolic clearance rate. Background counts were obtained in the testosterone fraction, indicating the absence of conversion by whole blood itself or the alumina or paper chromatographic systems employed in these studies.

\section{Results}

Metabolic clearance rate. The metabolic clearance rates of androstenedione (MCR ${ }^{\mathbf{A}}$ ) by continuous infusion, were $2,430 \pm 150$ (SE) L per day (6 subjects) in the male and $2,230 \pm 190$ (SE) L per day (6 subjects) in the female. There was no significant difference in values in both sexes, and the combined values were $2,330 \pm 107$ (SE) L per day ( 12 subjects) (Table I).

The metabolic clearance rate of testosterone $\left(\mathrm{MCR}^{\mathrm{T}}\right)$ by continuous infusion was $1,110 \mathrm{~L}$ per day in males ( 3 subjects) and $892 \mathrm{~L}$ per day ( 3 subjects, including one value of $916 \mathrm{~L}$ per day not in Table I) in females. When these values were combined with those recently reported by one of the authors ( 3$)$, the combined male values were $1,018 \pm 74$ ( $\mathrm{SE})$ (8 male subjects) and $894 \pm$ 47 (SE) L per day (5 female subjects), and again there was no significant difference between male 
and female values with the number of subjects used, and the combined values were $980 \pm 54$ (SE) L per day (13 subjects).

Plasma concentration of androstenedione and testosterone. The values for androstenedione in plasma were $0.060 \pm 0.004$ (SE) $\mu \mathrm{g}$ per $100 \mathrm{ml}$ (12 subjects) in males and $0.140 \pm 0.008$ (SE) $\mu \mathrm{g}$ per $100 \mathrm{ml}$ (16 subjects) in females. These values were corrected for the mean blank value of the method (water and plasma from ovariectomized-adrenalectomized subjects) (12). Testosterone values in the normal male have been reported as $0.80 \pm 0.07$ (SE) $\mu \mathrm{g}$ per $100 \mathrm{ml}$ plasma (11 subjects) (11) and $0.034 \mu \mathrm{g} \pm 0.008$ (SE) $\mu \mathrm{g}$ per $100 \mathrm{ml}$ plasma (60 subjects) for females with the thiosemicarbazide- ${ }^{35} \mathrm{~S}$ method (14). Female values for testosterone in the group studied here were $0.040 \pm 0.007$ (SE) $\mu \mathrm{g}$ per $100 \mathrm{ml}$ plasma ( 8 subjects). There was thus no significant difference in values of testosterone in our group and those of Lobotsky, Wyss, Segre, and Lloyd (14), which were obtained by the same method. The mean of both of these groups was therefore taken for the following calculations. Values for androstenedione taken at the beginning of the infusion study, $0.110 \mu \mathrm{g}$ per $100 \mathrm{ml}$ for the male (6 subjects) and $0.172 \mu \mathrm{g}$ per $100 \mathrm{ml}$ (4 subjects) in the female, were somewhat higher than those obtained in the basal state. These slightly higher values might be the result of the anticipated stress of the procedure, which has also been shown to elevate progesterone in plasma (15). These elevated values have not been included in the following calculations.

Production rate in blood. The production rate in blood was calculated as the product of metabolic clearance rate $\left(\mathrm{MCR}^{\mathbf{T}}\right.$ and $\mathrm{MCR}^{\mathbf{A}}$ ) and plasma concentration ( $\mathrm{i}^{\mathrm{T}}$ and $\mathrm{i}^{\mathrm{A}}$ ) (16). The production rate in blood is therefore $3.4 \mathrm{mg}$ per day in the female and $1.4 \mathrm{mg}$ per day in the male for androstenedione and $0.34 \mathrm{mg}$ per day for the female and $7.8 \mathrm{mg}$ per day for the male for testosterone.

Conversion ratios in blood. The conversion ratios, $\mathrm{C}_{\mathbf{B B}}{ }^{{ }^{T} \mathrm{~T}}$ and $\mathrm{C}_{\mathbf{B B}}{ }^{\mathrm{TA}}$, are calculated as the ratio of counts per minute per liter of plasma of product to precursor, both corrected for recovery after infusion of precursor. The subscript letters on the symbol refer to infusion and measurement in blood, the superscript to the infused and measured steroid. The conversion ratio of androstenedione/

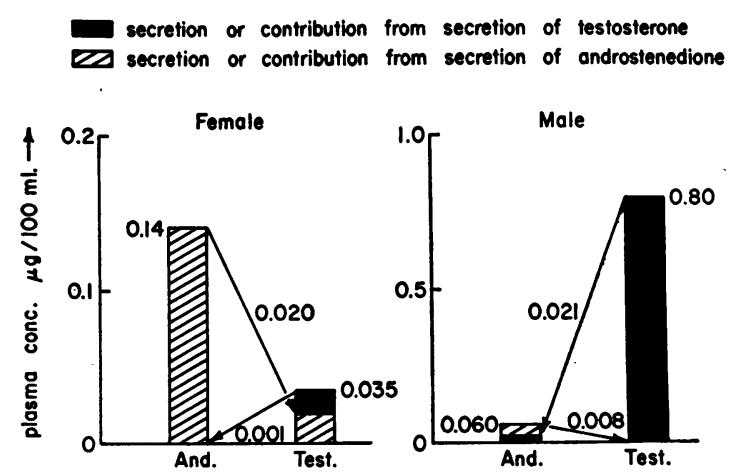

Fig. 1. Plasma concentrations and interconverSIONS OF ANDROSTENEDIONE/TESTOSTERONE IN BLOOD ( C $_{\text {BB }}{ }^{\Delta T}$ $=14 \%, \mathrm{C}_{\mathrm{BB}}^{\mathrm{TA}}=2.8 \%$ ).

testosterone $\left(\mathrm{C}_{\mathbf{B B}}{ }^{\mathbf{T A}}=\mathrm{z}^{\mathbf{A}} / \mathbf{z}^{\mathbf{T}}\right)$ after infusion of testosterone was $2.8 \pm 0.2 \%$ ( $\mathrm{SE}$ ) (5 subjects). The conversion ratio of testosterone/androstenedione $\left[\mathrm{C}_{\mathbf{B B}}{ }^{\mathbf{A T}}=\mathrm{x}^{\mathbf{T}} / \mathrm{x}^{\mathbf{A}}\right.$ was $14 \pm 1 \%$ (SE) (12 subjects) $]$. There was no significant difference between the male $13 \pm 2.5 \%$ ( $\mathrm{SE}$ ) (6 subjects) and female $14 \pm 1 \%$ ( $\mathrm{SE}$ ) (6 subjects) conversion ratios $\left(\mathrm{C}_{\mathbf{B B}}{ }^{\mathbf{A T}}\right)$ (Table I).

The contribution of androstenedione in blood to circulating testosterone. Since the conversion ratio of androstenedione/testosterone after infusion of testosterone $\left(\mathrm{C}_{\mathbf{B B}}{ }^{\mathrm{TA}}\right)$ is only $2.8 \%$, the contribution of plasma testosterone to plasma androstenedione in the female $(0.035 \times 0.028=<0.001$ $=<0.1 \%)$ is insignificant. However, the product of the higher concentration of androstenedione $(0.140 \mu \mathrm{g}$ per $100 \mathrm{ml})$ and reverse conversion ratio $\left(\mathrm{C}^{\mathrm{AT}}=14 \%\right)$ indicates that a significant amount $(0.020 \mu \mathrm{g}$ per $100 \mathrm{ml})$ of testosterone is derived from blood androstenedione. The actual total concentration of testosterone is $0.035 \mu \mathrm{g}$ per $100 \mathrm{ml}$. Thus the ratio $0.020 / 0.035 \mu \mathrm{g}$ per 100 $\mathrm{ml}$ indicates that $60 \%$ of testosterone in the female is derived from androstenedione in blood by peripheral conversion (Figure 1). In the male almost the opposite conclusion can be drawn. The contribution of plasma androstenedione to testosterone $(0.060 \times 0.014)$ is only $0.002 \mu \mathrm{g}$ per 100 $\mathrm{ml}$ or $<0.3 \%$ of plasma testosterone. However, due to the very small amount of androstenedione in male plasma in contrast to testosterone, the contribution of plasma testosterone to androstenedione is $0.022 \mu \mathrm{g}$ per $100 \mathrm{ml}(0.80 \times 0.028)$ or $36 \%$ of plasma androstenedione in the male (Figure 1). 
Transfer constants ([ $\rho]$ values) measured in blood after intravenous infusion. A transfer constant $[\rho]_{\text {BB }}$ for conversion of a precursor to product as measured in the peripheral blood can also be usefully and more generally defined as the fraction of the total amount of precursor entering the blood that enters the same circulation as the product. In this definition the total amount of product entering the blood before metabolism from the same circulation is measured, and the mechanism of the formation and further metabolism are irrelevant, e.g., it may be hepatic or extrahepatic. The $[\rho]_{\mathbf{B B}}{ }^{\mathbf{A T}}$ value for conversion of androstenedione to testosterone in blood is given by the rate of infusion of radioactive androstenedione $\left[\mathrm{Rx}^{\mathbf{A}}=\right.$ plasma radioactive concentration as androstenedione $\left(\mathrm{x}^{\boldsymbol{\Lambda}}\right)$ multiplied by the MCR of androstenedione $\left(\mathrm{MCR}^{\mathbf{A}}\right)$ ] and the rate of appearance of radioactive testosterone $\left[\mathrm{Rx}^{\mathbf{T}}=\right.$ plasma radioactive concentration of testosterone $\left(\mathbf{x}^{\mathbf{T}}\right)$ multiplied by the MCR of testosterone $\left.\left(\mathrm{MCR}^{\mathrm{T}}\right)\right]$.

Therefore,

$$
[\rho]_{\mathrm{BB}^{\mathrm{AT}}}=\frac{\mathrm{Rx}^{\mathrm{T}}}{\mathrm{Rx}^{\mathrm{A}}}=\frac{\mathrm{MCR}^{\mathrm{T}}}{\mathrm{MCR}^{\mathbf{A}}} \times \frac{\mathrm{x}^{\mathrm{T}}}{\mathrm{x}^{\mathbf{A}}},
$$

and

$$
[\rho]_{\mathrm{BB}}{ }^{\mathrm{TA}}=\frac{\mathrm{Rz}^{\mathrm{A}}}{\mathrm{Rz}^{\mathrm{T}}}=\frac{\mathrm{MCR}^{\mathrm{A}}}{\mathrm{MCR}^{\mathrm{T}}} \times \frac{z^{\mathrm{A}}}{z^{\mathbf{T}^{*}}} .
$$

From the values previously given,

and

$$
[\rho]_{\mathrm{BB}^{\mathrm{AT}}}=\frac{980}{2,330} \times 14 \%=5.9 \%,
$$

$$
[\rho]_{\mathrm{BB}}{ }^{\mathrm{TA}}=\frac{2,330}{980} \times 2.8 \%=6.6 \% .
$$

Therefore, $5.9 \%$ of intravenously infused androstenedione enters the blood as testosterone, and a similar per cent (6.6) of infused testosterone is converted to androstenedione.

The fraction of the blood production rate of testosterone $\left(\mathrm{P}_{\mathbf{B}} \mathbf{T}\right)$ coming from the blood production rate of androstenedione $\left(P_{B} \mathbf{A}\right)$ (but not including precursor originating from the product) is given by the expression (17),

$$
\frac{[\rho]_{\mathrm{BB}^{\mathrm{AT}} \mathrm{P}_{\mathrm{B}} \mathrm{A}}}{\mathrm{P}_{\mathrm{B}}{ }^{\mathrm{T}}} / 1-[\rho]_{\mathrm{BB}}{ }^{\mathrm{AT}}[\rho]_{\mathrm{BB}}{ }^{\mathrm{TA}},
$$

where $[\rho]_{\mathbf{B B}^{A T}} \mathbf{P}_{\mathbf{B}}{ }^{\mathbf{A}}$ is the production of testosterone in the blood arising from the production of androstenedione and $[\rho]_{\mathbf{B B}}{ }^{\Delta T} \mathrm{P}_{\mathbf{B}}{ }^{\mathbf{A}} / \mathrm{P}_{\mathbf{B}}{ }^{\mathrm{T}}$ is the fraction of total $\mathbf{P}_{\mathbf{B}}{ }^{T}$ made in this manner.

A similar expression,

$$
\frac{[\rho]_{\mathrm{BB}}^{\mathrm{TA}} \mathrm{P}_{\mathrm{B}}^{\mathrm{T}}}{\mathrm{P}_{\mathrm{B}}^{\mathrm{A}}} / 1-[\rho]_{\mathrm{BB}^{\mathrm{A}}}{ }^{\mathrm{T}}[\rho]_{\mathrm{BB}}{ }^{\mathrm{TA}},
$$

gives the fraction of the blood production of androstenedione coming from testosterone.

Usually in this type of calculation a correction $\left(1 / 1-[\rho]_{\mathbf{B B}}{ }^{\mathbf{A T}}[\boldsymbol{\rho}]_{\mathbf{B B}}{ }^{\mathbf{T A}}\right)$ has to be made because some of the precursor considered has arisen initially from the product. However, with the values presented here, $[\rho]_{\mathbf{B B}}{ }^{\mathbf{A T}}[\rho]_{\mathbf{B B}}{ }^{\mathrm{TA}}=0.059 \times 0.066$ $\ll 1$, and the correction is negligible.

The calculated fractions are the same in value as those already made in terms of plasma concentrations $\left(i^{\mathbf{T}}\right.$ and $\left.i^{\mathbf{A}}\right)$ and $\left(\mathbf{x}^{\mathbf{T}} / \mathbf{x}^{\mathbf{A}}\right)$ and $\left(\mathbf{z}^{\mathbf{A}} / \mathbf{z}^{\mathbf{T}}\right)$, as for example,

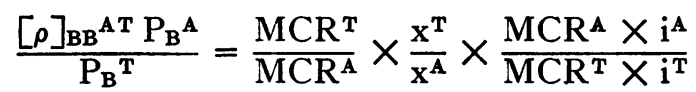

$$
\begin{aligned}
& =\frac{x^{T}}{x^{A}} \times \frac{i^{A}}{i^{T}}=\frac{C_{B B}{ }^{A T} \times i^{A}}{i^{T}} .
\end{aligned}
$$

Steroids in blood after oral infusions. An investigation into the site of the conversion of androstenedione to testosterone, e.g., whether this occurs in the splanchnic or extrasplanchnic circulation, requires measurement of the conversion rate in a situation where any possible extrasplanchnic conversion of androstenedione to testosterone is considerably reduced compared with when androstenedione is administered intravenously.

When androstenedione- ${ }^{14} \mathrm{C}$ was introduced by continuous infusion into the gastrointestinal tract, the fraction entering the general circulation as androstenedione could be calculated as ${ }^{14} \mathrm{C}$ radioactivity per liter plasma as androstenedione (corrected for losses) $\times \mathrm{MCR}^{\mathbf{A}}$ divided by rate of infusion of androstenedione-14 $\mathrm{C}$. In two experiments, this fraction was 0.103 and 0.023 , mean $6.3 \%$, taking $\mathrm{MCR}^{\mathrm{A}}=2,330 \mathrm{~L}$ per day. Therefore, in this situation, only $6.3 \% \times[\rho]_{\mathbf{B B}}{ }^{\mathbf{A T}}=6.3$ $\times 5.9=0.37 \%$ of the orally infused androstenedione could appear in the plasma as radioactive testosterone because of extrasplanchnic conversion of androstenedione, whereas after intravenous administration of androstenedione $5.9 \%$ could be converted in this manner. If the conversion of oral androstenedione to blood testosterone is not entirely extrasplanchnic, the conversion value will 
be even less than $0.37 \%$, and this is a maximal estimate. Efficient absorption by the intestinal tract was shown by the 85 and $88 \%$ total urinary recovery of ${ }^{14} \mathrm{C}$ in these experiments.

The fraction of orally infused androstenedione that enters the circulation as testosterone is similarly given by the expression, ${ }^{14} \mathrm{C}$ radioactivity per liter plasma as testosterone (corrected for losses) $\times \mathrm{MCR}^{\mathrm{T}}$ divided by the rate of infusion of androstenedione- ${ }^{14} \mathrm{C}$. This fraction was 1.9 and 1.8 in the two experiments ( 2 males). In two other experiments ( 1 male, 1 female) testosterone${ }^{3} \mathrm{H}$ was infused intravenously simultaneously with the oral infusion of androstenedione- ${ }^{14} \mathrm{C}$. The fraction of androstenedione in the general circulation as testosterone can then be calculated by the expression (which is equivalent to the one given above), ${ }^{14} \mathrm{C} /{ }^{8} \mathrm{H}$ as plasma testosterone $\div{ }^{14} \mathrm{C} /{ }^{3} \mathrm{H}$ of infused steroids in equivalent time interval. The estimates obtained were 1.2 (male) and 2.3 (female), which are in reasonable agreement with those obtained in the first two experiments, which used an $\mathrm{MCR}^{\mathrm{T}}$ value from other data. The mean of the four estimates was $1.8 \%$.

As a maximum of $0.37 \%$ of the oral androstenedione in plasma as testosterone could arise by extrasplanchnic conversion, as previously calculated, it seems that most of the total conversion of $1.8 \%$ originates from testosterone produced in the liver.

In the last two experiments, the ${ }^{14} \mathrm{C} /{ }^{3} \mathrm{H}$ ratio of testosterone released from urinary testosterone glucuronide was also measured. The ${ }^{14} \mathrm{C} /{ }^{3} \mathrm{H}$ ratio of this urinary testosterone divided by the ${ }^{14} \mathrm{C} /{ }^{3} \mathrm{H}$ ratio of the infused material gave values of 100 and 79 , mean $89 \%$, from which it can be concluded that the absorption of androstenedione by the intestinal tract and its conversion to testosterone in the liver are highly efficient if testosterone glucuronide is made hepatically. If $89 \%$ of the oral androstenedione is converted to testosterone in the liver, then $(1.8 / 0.89)=2.0 \%$ of testosterone produced hepatically must enter the circulation, or the hepatic extraction of testosterone produced in this manner is $98.0 \%$. A more direct calculation can be made from the results of the last two experiments by using the expression, ${ }^{14} \mathrm{C} /{ }^{3} \mathrm{H}$ of blood testosterone divided by ${ }^{14} \mathrm{C} /{ }^{3} \mathrm{H}$ of urinary testosterone. The values obtained in this manner were 1.2 and $2.3 \%$ for steroid entering the circulation as a fraction of the testosterone produced in the liver and 98.8 and 97.7 (mean $98.2 \%$ ) for hepatic extraction.

5 The calculation of the conversion of androstenedione, whether administered orally or intravenously, to testos-

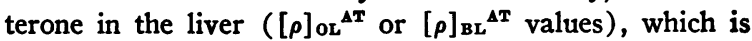
made by comparing the conversion of the oral or intravenous precursor and intravenously administered testosterone to urinary testosterone glucuronide, depends on the following assumptions: 1) Testosterone glucuronide is produced hepatically. This will be discussed in the text. 2) The testosterone is not made extrasplanchnically relative to the amounts made in the splanchnic circulation. As regards the oral administration of androstenedione, the appropriate relative quantities are $<0.4$ extrasplanchnic and $89 \%$ splanchnic, for intravenous injection 5.9 extrasplanchnic and $40 \%$ splanchnic. Therefore, this is a reasonable approximation. 3) Intravenously administered testosterone is not metabolized extrasplanchnically. The low MCR of testosterone indicates that this is probably so, but this assumption remains a possible source of error. 4) The fraction of testosterone made from androstenedione in the liver is converted to testosterone glucuronide to the same extent as testosterone entering the splanchnic circulation from intravenous administration. This assumption is a possible major uncertainty in the calculations of the amount of testosterone produced from androstenedione in the liver.

In the comparison of the conversion of oral and intravenous androstenedione to testosterone in the liver, these four assumptions are involved, but the first two are probably valid. Assumptions 3 and 4 are more uncertain. However, as in both types of experiment the conversion of androstenedione to urinary testosterone glucuronide was compared to that of intravenously administered testosterone, any correction due to the failure of assumptions 3 and 4 will be common to both calculations, and the comparison will be valid.

The calculations of hepatic extraction ( $\mathrm{H}$ ) will be affected by any failure in all four assumptions, as $\mathrm{H}=1$ $-[\rho]_{\mathrm{OB}}{ }^{\Delta \mathrm{T}} /[\rho]_{\mathrm{OS}}{ }^{\Delta \mathrm{T}}$ and the fraction transferred from liver to the blood of such testosterone $[\rho]_{\mathrm{LB}}{ }^{\mathrm{TT}}=[\rho]_{\mathrm{OB}}{ }^{\mathrm{AT}} /[\rho]_{\mathrm{OL}}{ }^{\mathbf{T T}}$. However, the contribution to blood testosterone from dehydroepiandrosterone will be $\mathrm{P}^{\mathrm{D}} \times[\rho]_{\mathrm{BL}}{ }^{\mathrm{DT}} \times[\rho]_{\mathrm{LB}}{ }^{\mathrm{TT}}=$ $\mathrm{P}^{\mathrm{D}} \times[\rho]_{\mathrm{BL}}{ }^{\mathrm{DT}} \times\left([\rho]_{\mathrm{OB}}{ }^{\Delta \mathrm{T}} /[\rho]_{\mathrm{OL}}{ }^{\Delta \mathrm{T}}\right)$. $[\rho]_{\mathrm{BL}}{ }^{\mathrm{DT}}$ in the numerator and $[\rho]_{0 \mathbf{S}}{ }^{\Delta \mathbf{T}}$ in the denominator will be affected by the failure of assumption 3 to the same extent, and hence any correction factor due to this will cancel. As 1 and 2 are reasonable assumptions, the major uncertainties in the treatment of contributions from dehydroepiandrosterone will therefore be assumption 4 and that the hepatic extraction and conversion of testosterone made from androstenedione, which has itself been formed from dehydroepiandrosterone in the liver, are the same as testosterone made hepatically from androstenedione entering the liver after being administered orally or intravenously. Comparison of the maximal hepatic extractions of testosterone from the clearance rate values $(60 \%)$ and from oral administration of androstenedione ( $>98 \%$ ) does suggest that testosterone made hepatically from andros- 


\section{Discussion}

Since in normal man the hepatic plasma flow is $1,600 \mathrm{~L}$ per day (19), metabolic clearance rates of steroids that exceed this value indicate significant extrahepatic metabolism even if the hepatic extraction is $100 \%$. The finding that the clearance rate of androstenedione is $2,330 \mathrm{~L}$ per day indicates that at least one-third of the total metabolism must be extrahepatic. If the hepatic extraction were less than $100 \%$, the proportion of extrahepatic metabolism would be even greater. It seems unlikely that this amount of extrahepatic clearance could be due to conversion of androstenedione to testosterone, as only $6 \%\left([\rho]_{\mathrm{BB}}{ }^{\mathrm{AT}}\right)$ of intravenous infused androstenedione is metabolized in this manner. It seems more likely that the $5 \alpha$ - and $5 \beta$-androsterones or other metabolites or both are formed from androstenedione both in the liver and extrahepatically.

The metabolic clearance rate of testosterone as determined by a single injection procedure has been reported as $965 \mathrm{~L}$ per day by Horton, Shinsako, and Forsham (3) with similar values by Hudson, Coghlan, Dulmanis, and Wintour (7). These estimates are not significantly different from those obtained by a continuous infusion procedure in this study. The infusion method is, however, in many respects technically simpler to perform, and it allows for easier testing of attainment of equilibrium and calculation of results and errors. As has been previously discussed (3), this MCR value of testosterone indicates a maximal hepatic extraction of about $60 \%$ for this steroid

tenedione is metabolized differently from preformed testosterone entering the liver although the validity of assumption 4 is involved in this conclusion. However, Migeon (18) has obtained a value of $50 \%$ for the splanchnic extraction of testosterone entering the liver by direct analysis of hepatic venous blood. Also, urinary data indicate that the metabolism of androstenedione depends on whether it is secreted or formed from dehydroepiandrosterone (8). Nevertheless, the vital assumption made in the calculation of the contribution from dehydroepiandrosterone is that the metabolism of testosterone formed from androstenedione does not depend on the source of the androstenedione. Although this assumption has not been rigorously tested in the present studies because of the difficulties in devising a meaningful experiment, it appears to be more likely to be true than that the metabolism of a steroid depends on whether it is preformed or converted at the site of the metabolism from a precursor. when administered intravenously, which suggests that it may be bound to some extent to plasma proteins other than albumin (4).

The production rates of a steroid in plasma (blood production rate) can be calculated as the product of its metabolic clearance rate and mean plasma concentration (5). In the case of interconverting compounds, the blood production rate is the sum of steroid directly secreted plus that synthesized peripherally that enters the blood $(4,5)$. The blood production rates of androstenedione calculated from the data obtained in these studies are 3.4 and $1.4 \mathrm{mg}$ per day in the female and male, respectively. Vande Wiele, MacDonald, Gurpide, and Lieberman (2) calculated urinary production rates of androstenedione in both sexes as about $10 \mathrm{mg}$ per day by measuring the specific activities of urinary $5 \alpha$ - and $5 \beta$-androsterones. This is another example of discrepancies (5) in the estimates of urinary and blood production rates. These discrepancies could be due to production of androstenedione from precursors such as testosterone and dehydroepiandrosterone that do not enter the general circulation, perhaps because of appreciable hepatic extraction, but do lead to formation of $5 \alpha$ - and $5 \beta$-androsterone. The larger discrepancy in the male compared with the female could be due to a secretion of more precursor as testosterone and hence production of androstenedione by conversion relative to the amount of androstenedione that enters the blood directly by secretion. Similarly, the blood production rates of testosterone are 7 and $0.34 \mathrm{mg}$ per day in the male and female, whereas the corresponding urinary production rates calculated from the specific activity of urinary testosterone glucuronide are 7 and $1.8 \mathrm{mg}$ per day (3). The lack of discrepancy in the urinary and blood production rates of testosterone in the male is due to the relatively low blood production rate (1.4 mg per day) of the major precursor, androstenedione, compared with the blood production rate of testosterone $(7 \mathrm{mg}$ per day). However, in the female the blood production rates of androstenedione and testosterone are 3.4 and $0.34 \mathrm{mg}$ per day, respectively. About $40 \%$ of the blood androstenedione (i.e., $1.4 \mathrm{mg}$ per day) would be converted to testosterone, which gives rise to urinary testosterone glucuronide according to several groups of investigators $(2,7,9,10,20)$, but only $6 \%,[\rho]_{\mathrm{BB}}{ }^{\mathrm{AT}}$, or $0.2 \mathrm{mg}$ 
per day would contribute to the blood production of testosterone. These new data on androstenedione therefore support previous calculations regarding testosterone (10) and the general conclusion $(3,5,6,9,10)$ that although urinary production rates may give estimates of the total synthesis of steroid in the body, they do not always give the amount of steroid entering the general circulation.

Consideration of the concentration of testosterone in female plasma $(0.035 \mu \mathrm{g}$ per $100 \mathrm{ml})$ and the ratio of radioactivity measured as androstenedione to testosterone $\left(z^{\mathbf{A}} / \mathbf{z}^{\mathbf{T}}=0.028\right)$ after intravenous administration of labeled testosterone shows that a negligible proportion of the total plasma concentration of androstenedione (0.14 $\mu \mathrm{g}$ per $100 \mathrm{ml}$ ) is due to plasma testosterone. However, as the ratio of radioactivity measured as testosterone to androstenedione $\left(\mathrm{x}^{\mathrm{T}} / \mathrm{x}^{\mathbf{A}}\right)$ after intravenous infusion of androstenedione is 0.14 , then 0.02 of $0.035 \mu \mathrm{g}$ per $100 \mathrm{ml}$ or $60 \%$ of the plasma testosterone is converted from plasma androstenedione. Forty per cent of the plasma testosterone in the female must, therefore, come from sources that do not contribute to plasma androstenedione. Similar calculations can be made with blood production rates and transfer constants ( $\rho]$ values) with identical conclusions regarding the proportion of product made from precursor in the plasma. As the interconversion rates seem to be the same in both sexes, it can also be calculated that in the male a negligible amount of plasma testosterone comes from plasma androstenedione but 0.022 of a total of $0.060 \mu \mathrm{g}$ per $100 \mathrm{ml}$ or $36 \%$ of the plasma androstenedione is converted from plasma testosterone (Figure 1).

The fraction of precursor converted to product in plasma (the [ $\rho]$ values) is similar for androstenedione to testosterone $\left([\rho]_{\mathbf{B B}}{ }^{\mathbf{A T}}=5.9 \%\right)$ and for the reverse process $\left([\rho]_{\mathrm{BB}}{ }^{\mathrm{TA}}=6.6 \%\right)$. When labeled androstenedione is given intravenously, the steroid is available for both splanchnic and extrasplanchnic conversion although some of the testosterone produced may not enter the general circulation. Therefore, the determination of $[\rho]_{\mathrm{BB}}{ }^{\mathrm{AT}}$ as $5.9 \%$ by intravenous infusion gives no information as to the site of the conversion. When labeled androstenedione is given by oral infusion, however, only $6.3 \%$ of this precursor enters the general circulation as androstenedione itself, and the possibility of radioactivity as testosterone in plasma being formed $\left(<6.3 \times[\rho]_{\mathbf{B B}}{ }^{\mathbf{A T}}\right)$ extrahepatically by conversion from androstenedione is considerably reduced $(<6.3 \times 5.9<$ $0.37 \%$ ). Actually, $1.8 \%$ of the orally infused androstenedione enters the plasma as testosterone compared with $5.9 \%$ after intravenous androstenedione. If, therefore, it could be assumed that orally infused androstenedione enters and is converted to testosterone in the liver as effectively as intravenously administered androstenedione, at least $70 \%[(5.9-1.8) / 5.9]$ of the plasma testosterone converted from plasma androstenedione is made extrasplanchnically. This assumption seems reasonable, as $89 \%$ of orally administered androstenedione is converted to urinary testosterone glucuronide compared with intravenously administered testosterone, whereas the corresponding value after intravenous injection of both androstenedione and testosterone is about $40 \%(2,7,9,10,20) .^{5}$ Little testosterone enters the general circulation after oral administration of androstenedione, indicating that urinary testosterone glucuronide is formed in the splanchnic circulation. The higher conversion of androstenedione to testosterone when given orally compared with intravenous administration is reasonable in view of the high recovery of radioactivity in urine after oral androstenedione, indicating efficient absorption of this steroid by the intestinal tract, and the evidence previously discussed that androstenedione is appreciably metabolized extrahepatically to compounds other than testosterone when given intravenously. As a small but significant proportion of the testosterone in plasma after oral administration of androstenedione $(0.37$ out of $1.8 \%)$ is converted from plasma androstenedione and more testosterone is formed in the liver after oral than after intravenous infusion of androstenedione, it seems reasonable to conclude that a negligible proportion of the testosterone in plasma from intravenous androstenedione is made originally in the splanchnic circulation and that the process largely occurs in extrasplanchnic tissues. The exact anatomical sites of this conversion are still unknown. It is unlikely to be in blood itself according to the study previously described here. Thomas and Dorfman have reported that this conversion may occur in the muscle of the rat (21).

$\mathrm{A}[\rho]_{\mathbf{B B}}{ }^{\mathbf{A T}}$ value can also be calculated from the 
data of Korenman and Lipsett, who measured the ${ }^{8} \mathrm{H} /{ }^{14} \mathrm{C}$ ratio of the testosterone in plasma and urinary testosterone glucuronide after a single injection of androstenedione- ${ }^{8} \mathrm{H}$ and testosterone $-{ }^{14} \mathrm{C}$ (10). The two values, where this can be calculated, are 8.0 and $5.8 \%$, which are in reasonable agreement with our mean value of 5.9. However, Korenman and Lipsett then assumed that extrasplanchnic conversion of androstenedione to testosterone was negligible and that the testosterone converted from androstenedione appearing in the plasma came from the liver. The splanchnic extraction of the testosterone formed in the liver (the per cent testosterone formed there that is irreversibly metabolized) could then be calculated as 75 and $83 \%$ in the two experiments. Korenman and Lipsett clearly stated the assumption involved in this calculation, but the only relevant experimental evidence presented was the lack of rapid conversion in vitro in blood. We have confirmed this observation, but this does not eliminate the possibility of conversion of androstenedione to testosterone in extrasplanchnic tissue. The experiments described here in which androstenedione was given orally suggest a much higher splanchnic extraction of testosterone formed in the liver from androstenedione and formation of plasma testosterone mainly by extrasplanchnic conversion of androstenedione. This calculation does not depend on any assumption involving extrasplanchnic conversion but instead that the conversion of androstenedione to testosterone is negligible before the radioactive steroid enters the hepatic portal circulation. This is apart from the other assumptions and considerations detailed in footnote 5 , which are also common to the conclusions of Korenman and Lipsett. If either the orally administered androstenedione- ${ }^{14} \mathrm{C}$ or formed testosterone was metabolized to compounds other than testosterone glucuronide before entering the portal circulation, this would not affect the validity of the calculations as this is allowed for in the yield of ${ }^{14} \mathrm{C}$-labeled urinary testosterone glucuronide. If the testosterone formed in the gut were not metabolized before entering the portal circulation, this would affect the calculation and give rise to an overestimate in the value for the splanchnic extraction. However, from the MCR value of testosterone, as previously discussed, the maximal splanchnic extraction of testosterone entering the liver would be about $60 \%$. Recently, Migeon (18) has measured the extraction of testosterone presented to the liver by direct hepatic venous blood analysis and found it to be about 50\% (although the hepatic extraction of androstenedione measured at the same time was nearly $100 \%$ ). Thus if appreciable amounts of testosterone formed from the oral androstenedione entered the portal circulation, much larger amounts than were measured would be expected to enter the peripheral circulation. The remaining possibility to be considered is that little testosterone enters the portal circulation but that appreciable amounts of testosterone and testosterone glucuronide were formed in the gut from the oral androstenedione. This possibility would mean that the gut is highly efficient in metabolizing testosterone and that appreciable amounts of testosterone glucuronide are also formed there. This possibility has not been disproved experimentally in the present studies, but it seems much less likely then that the assumption that extrasplanchnic conversion of androstenedione to testosterone is negligible, which gives rise to the lower estimate of splanchnic extraction.

Forty per cent $(0.04 \mu \mathrm{g}$ per $100 \mathrm{ml}$ or $0.14 \mathrm{mg}$ per day) of the plasma testosterone in the female is not formed from plasma androstenedione. This proportion could be due to testosterone 1) secreted directly into the general circulation or 2) formed from a source of androstenedione that does not enter the peripheral blood or 3) produced by a chemical pathway not including androstenedione as an intermediate. As regards 3, that this could be due to testosterone formed by hydrolysis from secreted testosterone glucuronide seems unlikely from the available evidence. There is a possibility, however, that other pathways such as through secretion of $\Delta^{5}$-androstenediol, which could be converted to testosterone without going through androstenedione, could make a contribution that would lead to an overestimate of the secretion ratio. As regards the second possibility, androstenedione formed from dehydroepiandrosterone in the liver may not enter the general circulation but may form testosterone hepatically; this product may contribute significantly to blood testosterone. The oral experiments indicate that the hepatic extraction of testosterone formed from oral androstenedione is at least $98 \%$. Data in the literature indicate that 4 to $10 \%$ of intravenously 
administered dehydroepiandrosterone is converted to testosterone glucuronide compared to the similar conversion of intravenous testosterone $(2,9)$, indicating that 4 to $10 \%$ of the production rate of dehydroepiandrosterone is converted to testosterone hepatically. Production rates of dehydroepiandrosterone have been reported as about $10 \mathrm{mg}$ per day in both sexes (2). This would indicate a production rate of testosterone from dehydroepiandrosterone in the liver of about $0.6 \mathrm{mg}$ per day of which a maximum of $0.01 \mathrm{mg}$ per day would enter the general circulation. These calculations therefore show that this source of androstenedione (or other pathways from dehydroepiandrosterone leading to production of testosterone in the liver) is unlikely to give rise to a significant amount of plasma testosterone ( $<0.01$ of $0.34 \mathrm{mg}$ per day) even in the female. ${ }^{5}$ This conclusion is supported by the minimal $(<20 \%)$ elevation of plasma testosterone resulting from prolonged administration of ACTH despite marked increases in total urinary 17-ketosteroids (22). This result also indicates that extrasplanchnic conversion of dehydroepiandrosterone, whatever the chemical pathway, e.g., through androstenedione or $\Delta^{5}$-androstenediol, is not a major factor in contributing to blood testosterone.

Therefore, it can be concluded that secretion of testosterone ( 0.14 of 0.34 total $\mathrm{mg}$ per day) is the probable major source of plasma testosterone not derived from plasma androstenedione $(0.20$ of 0.34 total $\mathrm{mg}$ per day), although theoretically some of this $0.14 \mathrm{mg}$ per day could be due to conversion from precursors such as secreted $\Delta^{5}$ androstenediol.

All the plasma androstenedione in the female originates from a source other than plasma testosterone. A conclusion that this must be due to secretion of androstenedione seems likely, but must be less certain than the conclusion that the source of testosterone in the female is not from plasma androstenedione. This is because although the high clearance rate of androstenedione and the low $[\rho]_{\mathbf{B B}}{ }^{\text {TA }}$ value [taken together with urinary data indicating that testosterone is very efficiently converted to androstenedione hepatically $(2,20)]$ also suggest nearly complete extraction of androstenedione made from a precursor, testosterone, the metabolism of other precursors such as dehydroepiandrosterone preferably after oral and intrave- nous infusion has not yet been studied. As $60 \%$ of plasma testosterone is made from plasma androstenedione, it seems that the ACTH experiments also indicate that dehydroepiandrosterone does not contribute significantly to plasma androstenedione. Also, it has been found that plasma androstenedione is not raised in female subjects during acute surgery (23). Nevertheless, the possible contributions of other precursors such as 17-hydroxyprogesterone although unlikely to be significant have not been thoroughly considered. Therefore, although it can be concluded that the secretion of androstenedione in the female is probably about $3.4 \mathrm{mg}$ per day, or nearly all the blood production rates, this estimate must be viewed with some reservations. The estimate of the secretion of testosterone is more certain, as the appropriate major immediate precursor, androstenedione, whether it is secreted or produced from dehydroepiandrosterone or other compounds such as 17-hydroxyprogesterone, has been considered more rigorously in the calculations. Nevertheless, it seems likely that the blood production rate of androstenedione in the female is due to secreted androstenedione, and if this is so then this compound can be considered the major secreted androgen in young adults of this sex insofar as, even if it has no intrinsic biological activity of its own, it gives rise to most of the circulating testosterone, the most active naturally occurring androgen known. The reason, if any, for secretion or production of a precursor rather than the final hormone in the female but not in the male is an intriguing question that remains to be investigated.

The values of $<1 \mu \mathrm{g}$ androstenedione per 100 $\mathrm{ml}$ plasma from normal female ovarian venous blood (24), which have been confirmed by the thiosemicarbazide- ${ }^{85} \mathrm{~S}$ method (23), and about 10 $\mu \mathrm{g}$ androstenedione per $100 \mathrm{ml}$ plasma in normal female adrenal venous blood $(25,26)$ would suggest that the adrenal and not the ovary is the major source of secreted androstenedione in the female if the blood flows through the two endocrine organs are comparable. However, Wieland and his colleagues (25) conclude that this adrenal androstenedione is under ACTH control, whereas as blood testosterone is not increased by ACTH, our evidence would suggest that secreted androstenedione is also not affected by this pituitary hormone in the female. Further studies on the source 
of androstenedione are needed to explain this discrepancy.

\section{Summary}

The androstenedione metabolic clearance rate, production rate in blood, and conversion rate to blood testosterone have been determined by analysis of plasma concentration of steroid by a double isotope derivative technique and by measurement of radioactivity as precursor and product steroid in plasma after introduction of labeled precursors into the general circulation. The metabolic clearance rate of androstenedione is $2,330 \pm 107$ (SE) $\mathrm{L}$ per day indicating considerable extrahepatic metabolism, whereas the metabolic clearance rate of testosterone [980 \pm 54 (SE) L per day] suggests a hepatic extraction of secreted testosterone considerably less than $100 \%$. The blood production rate of androstenedione is $3.4 \mathrm{mg}$ per day in the female and $1.4 \mathrm{mg}$ per day in the male compared with testosterone blood production rates of 0.34 and $7 \mathrm{mg}$ per day, respectively. Consideration of the production rates in plasma of testosterone and androstenedione offers an explanation of the agreement in production rates in blood or urine of testosterone in males, and of the considerable discrepancy in the corresponding estimates in females due to the marked relative predominance of androstenedione as precursor in the blood of females. The determination of conversion rates in blood indicates that essentially no androstenedione arises from blood testosterone in the female; however, $60 \%$ of plasma testosterone results from the peripheral conversion of plasma androstenedione. The remaining $40 \%$ is probably due to secretion of testosterone or, less likely, conversion from precursors such as secreted $\Delta^{5}$-androstenediol. Finally, the very low radioactivity as testosterone in plasma after the oral administration of labeled androstenedione suggests that the primary site of the conversion of blood androstenedione to blood testosterone is extrasplanchnic.

The determination of production and secretion rates of these interconverting hormones by analysis in blood may give more precise and relevant results than urinary or combined blood and urinary methods previously used for such calculations.

\section{Acknowledgments}

We are grateful for permission given by Dr. Charles Lloyd to quote some unpublished observations regarding the effect of ACTH on testosterone in plasma. Also we benefited by discussions with Drs. J. Coghlan, B. Hudson, and E. Baulieu.

\section{References}

1. Mahesh, V., and R. B. Greenblatt. The in vivo conversion of dehydroepiandrosterone and androstenedione to testosterone in the human. Acta endocr. (Kbh.) 1962, 41, 400.

2. Vande Wiele, R., P. MacDonald, E. Gurpide, and S. Lieberman. Studies on the secretion and interconversion of the androgens. Recent Progr. Hormone Res. 1963, 19, 275.

3. Horton, R., J. Shinsako, and P. H. Forsham. Testosterone production and metabolic clearance rates with volumes of distribution in normal adult men and women. Acta endocr. (Kbh.) 1965, 48, 446.

4. Tait, J. F., and S. Burstein. In vivo studies of steroid dynamics in man in The Hormones, G. Pincus, K. Thimann, and E. B. Astwood, Eds. New York, Academic Press, 1964, vol. 5, p. 441.

5. Tait, J. F. Review: the use of isotopic steroids for the measurement of production rates in vivo. J. clin. Endocr. 1963, 23, 1285.

6. Tait, J. F., and R. Horton. Some theoretical considerations on the significance of the discrepancy in urinary and blood production rate estimates of steroid hormones. Steroids 1964, 14, 365.

7. Hudson, B., J. P. Coghlan, A. Dulmanis, and M. Wintour. The measurement of testosterone in biological fluids in the evaluation of androgen activity. Proceedings of the Second International Congress of Endocrinology, London, 1964. Amsterdam, Excerpta Medica Foundation International Congress Series no. 83, 1965 , p. 1127.

8. Tait, J. F., and R. Horton. The in vivo estimation of blood production and interconversion rates of androstenedione and testosterone and the calculation of their secretion rates in Steroid Dynamics, G. Pincus, T. Nakao, and J. F. Tait, Eds. New York, Academic Press, 1966, in press.

9. Camacho, A., and C. J. Migeon. Studies on the origin of testosterone in the urine of normal adult subjects and patients with various endocrine disorders. J. clin. Invest. 1964, 43, 1083.

10. Korenman, S., and M. B. Lipsett. Is testosterone glucuronoside uniquely derived from plasma testosterone? J. clin. Invest. 1964, 43, 2125.

11. Riondel, A., J. F. Tait, M. Gut, S. A. S. Tait, E. Joachim, and B. Little. Estimation of testosterone in human peripheral blood using $\mathrm{S}^{35}$-thiosemicarbazide. J. clin. Endocr. 1963, 23, 620.

12. Horton, R. Estimation of androstenedione in human peripheral blood with ${ }^{85}$ S-thiosemicarbazide. J. clin. Endocr. 1965, 25, 1237. 
13. Tait, J. F., S. A. S. Tait, B. Little, and K. R. Laumas. The disappearance of $7-\mathrm{H}^{3}-d$-aldosterone in plasma of normal subjects. J. clin. Invest. 1961, 40, 72.

14. Lobotsky, J., H. I. Wyss, E. J. Segre, and C. W. Lloyd. Plasma testosterone in the normal woman. J. clin. Endocr. 1964, 24, 1261.

15. Riondel A., J. F. Tait, S. A. S. Tait, M. Gut, and B. Little. The estimation of progesterone in human peripheral blood using ${ }^{35} \mathrm{~S}$-thiosemicarbazide. J. clin. Endocr. 1965, 25, 229.

16. Horton, R., and J. F. Tait. Androstenedione: plasma concentration, production rate and conversion to plasma testosterone. Program of the Forty-seventh Meeting of the Endocrine Society, New York, 1965, p. 25.

17. Gurpide, E., J. Mann, and S. Lieberman. Analysis of open systems of multiple pools by administration of tracers at a constant rate or as a single dose as illustrated by problems involving steroid hormones. J. clin. Endocr. 1963, 23, 1155.

18. Migeon, C. in discussion of M. B. Lipsett. Some studies on Leydig cell physiology. Recent Progr. Hormone Res. 1966, 22, in press.

19. Bradley, S. E., F. J. Ingelfinger, G. P. Bradley, and J. J. Curry. The estimation of hepatic blood flow in man. J. clin. Invest. 1945, 24, 890.
20. Baulieu, E.-E., and P. Mauvais-Jarvis. Studies on testosterone metabolism. II. Metabolism of testosterone-4-14 $\mathrm{C}$ and androst-4-ene-3,17-dione-1,2- ${ }^{8} \mathrm{H}$. J. biol. Chem. 1963, 239, 1578.

21. Thomas, P. Z., and R. I. Dorfman. Metabolism in vitro of androst-4-ene-3,17-dione-4- ${ }^{14} \mathrm{C}$ by rabbit skeletal muscle strips. Isolation of testosterone${ }^{14} \mathrm{C}, 5 \alpha$-androstane-3,17-dione- ${ }^{14} \mathrm{C}$, and $3 \beta$-hydroxy$5 \alpha$-androstan-17-one- ${ }^{14}$ C. J. biol. Chem. 1964, 239, 762.

22. Lloyd, C. W. Personal communication.

23. Horton, R. Unpublished observation.

24. Mahesh, V. B. in discussion of R. I. Dorfman, E. Forchielli, and M. Gut. Androgen biosynthesis and related studies. Recent Progr. Hormone Res. 1963, 19, 269.

25. Wieland, R. G., C. de Courcy, R. P. Levy, A. P. $\mathrm{Zala}$, and $\mathrm{H}$. Hirschmann. $\mathrm{C}_{19} \mathrm{O}_{2}$ steroids and some of their precursors in blood from normal human adrenals. J. clin. Invest. 1965, 44, 159.

26. Weinheimer, B., G. W. Oertel, W. Leppla, H. Blaise, and L. Bette. Plasma steroid concentrations of adrenal venous blood from women with and without hirsutism. Abstracts of the Second Symposium on Steroid Hormones: Androgens in Normal and Pathological Conditions, Ghent, Belgium, June 1965. p. 53.

\section{ANNOUNCEMENT OF MEETINGS}

The American Federation for Clinical Research will hold its Twentythird Annual Meeting in Atlantic City, N. J., in the Pennsylvania Room, Haddon Hall, on Sunday, May 1, 1966, at 9:00 a.m. Joint sectional meetings with the American Society for Clinical Investigation will be held on Sunday afternoon at Chalfonte-Haddon Hall, and additional meetings sponsored by The American Federation for Clinical Research will be held on Sunday evening.

The American Society for Clinical Investigation, Inc., will hold its Fifty-eighth Annual Meeting in Atlantic City, N. J., on Monday, May 2, at 9:00 a.m., in the Pennsylvania Room, Haddon Hall, and will join The American Federation for Clinical Research in simultaneous sectional meetings on Sunday afternoon, May 1, at Chalfonte-Haddon Hall.

The Association of American Physicians will hold its Seventy-ninth Annual Meeting in Atlantic City, N. J., in the Pennsylvania Room, Haddon Hall, on Tuesday, May 3, at 9:30 a.m., and in the Carolina Room, Chalfonte, on Wednesday, May 4, at 9:30 a.m. 